\title{
Overview of Structural Behavior and Occupant Responses from a Crash Test of a Composite Airplane
}

Lisa E. Jones and Huey D. Carden NASA Langley Research Center

General, Corporate and Regional Aviation Meeting and Exposition Wichita, Kanas May 3-5, 1995 
The appearance of the ISSN code at the bottom of this page indicates SAE's consent that copies of the paper may be made for personal or internal use of specific clients. This consent is given on the condition, however, that the copier pay a $\$ 7.00$ per article copy fee through the Copyright Clearance Center, Inc. Operations Center, 222 Rosewood Drive, Danvers, MA 01923 for copying beyond that permitted by Sections 107 or 108 of the U.S. Copyright Law. This consent does not extend to other kinds of copying such as copying for general distribution, for advertising or promotional purposes, for creating new collective works, or for resale.

SAE routinely stocks printed papers for a period of three years following date of publication. Direct your orders to SAE Customer Sales and Satisfaction Department.

Quantity reprint rates can be obtained from the Customer Sales and Satisfaction Department.

To request permission to reprint a technical paper or permission to use copyrighted SAE publications in other works, contact the SAE Publications Group.

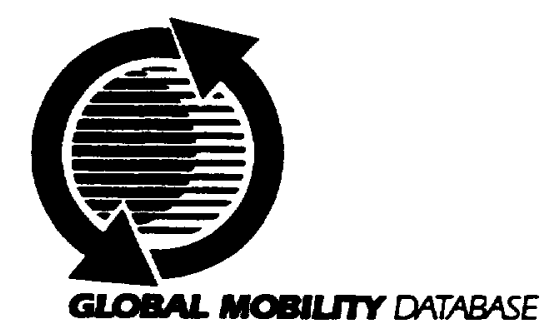

All SAE papers, standards, and selected books are abstracted and indexed in the Global Mobility Database.

No part of this publication may by reproduced in any form, in an electronic retrieval system or otherwise, without the prior written permission of the publisher.

\section{ISSN $0148-7191$}

Copyright 1995 Society of Automotive Engineers, Inc.

Positions and opinions advanced in this paper are those of the author(s) and not necessarily those of SAE. The author is solely responsible for the content of the paper. A process is available by which discussions will be printed with the paper if it is published in SAE transactions. For permission to publish this paper in full or in part, contact the SAE Publications Group.

Persons wishing to submit papers to be considered for presentation or publication through SAE should send the manuscript or a 300 word abstract of a proposed manuscript to: Secretary, Engineering Activity Board, SAE. 
The aircraft used for the test is a low-wing, twinengine, pusher propeller general aviation airplane with a carbon fibre reinforced composite skin and frame construction and an aluminum floor and subfloor. Both the wing span and length of the aircraft is about $\mathbf{4 0}$ feet. The design gross takeoff weight is $7200 \mathrm{lbs}$. with a capacity for eight occupants. Details of the original structure and development of the aircraft are given in Reference 3.

The fuselages acquired by NASA Langley Research Center were non-flying, ground test structures. Avionics, seats, engines, propellers, tails, and landing gear were not included. Consequently, a plywood dash board was constructed in the cockpit, seats were installed, weights were added to simulate the engines masses and propeller, and a tail was added to the test vehicle. Landing gear, without hydraulic systems or operating linkages, were installed for ease of handling as well as for ballast weight. The fuel cells were filled with water to simulate the fuel mass. Interior and exterior surfaces of the airplane were painted to enhance photographic contrast. A plywood bulkhead wall was installed in front of the most rearward pair of seats to accommodate the installation of the airbag experiment. A photograph of the test aircraft is shown in Figure 3 . The final ballasted weight of the test vehicle was 6989 lbs.

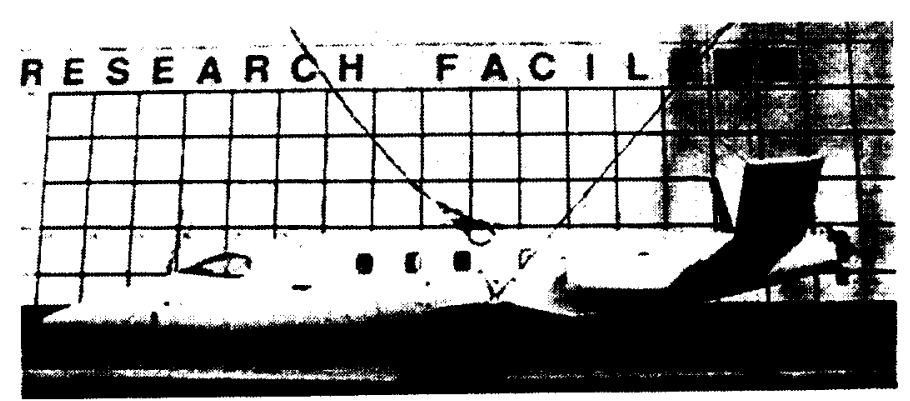

Figure 3. The test specimen.

The seating layout is shown in Figure 4(a). Unlike the original design (Reference 3 ), all seats were forward facing. Only seven seats were installed to provide room for onboard instrumentation and easier access. Note that each seat is numbered and henceforth the occupants will be referred to by the seat number assigned. For example, the pilot position is the number 1 occupant seat, copilot position is the number 2 occupant seat, and so on. Seats 1, 3, 6 and 7 were standard $9 \mathrm{~g}$ aircraft seats equipped with a lap belt only. Seat 2 was an energy absorbing seat that is currently installed in aircraft that fly into unprepared landing strips. The front legs of this seat are bent into an "S" shape and the back legs are slanted rearward to provide improved energy absorption due to bending. Seat 2 was equipped with a lap belt and shoulder harness. Photographs of a standard seat and certified seat are shown in Figure $4(\mathrm{~b})$. Seats 4 and 5 were seats provided by a university and are being developed through a grant with the Federal Aviation Administration (FAA). Seats 4 and 5 are designed to satisfy a proposed FAA dynamic crash test requirement. The seats were equipped with lap belts and shoulder harnesses and the design incorporates energy absorbing devices in the cushion and the chair legs. Additional information on the designs of seats 4 and 5 is given in Reference 4.

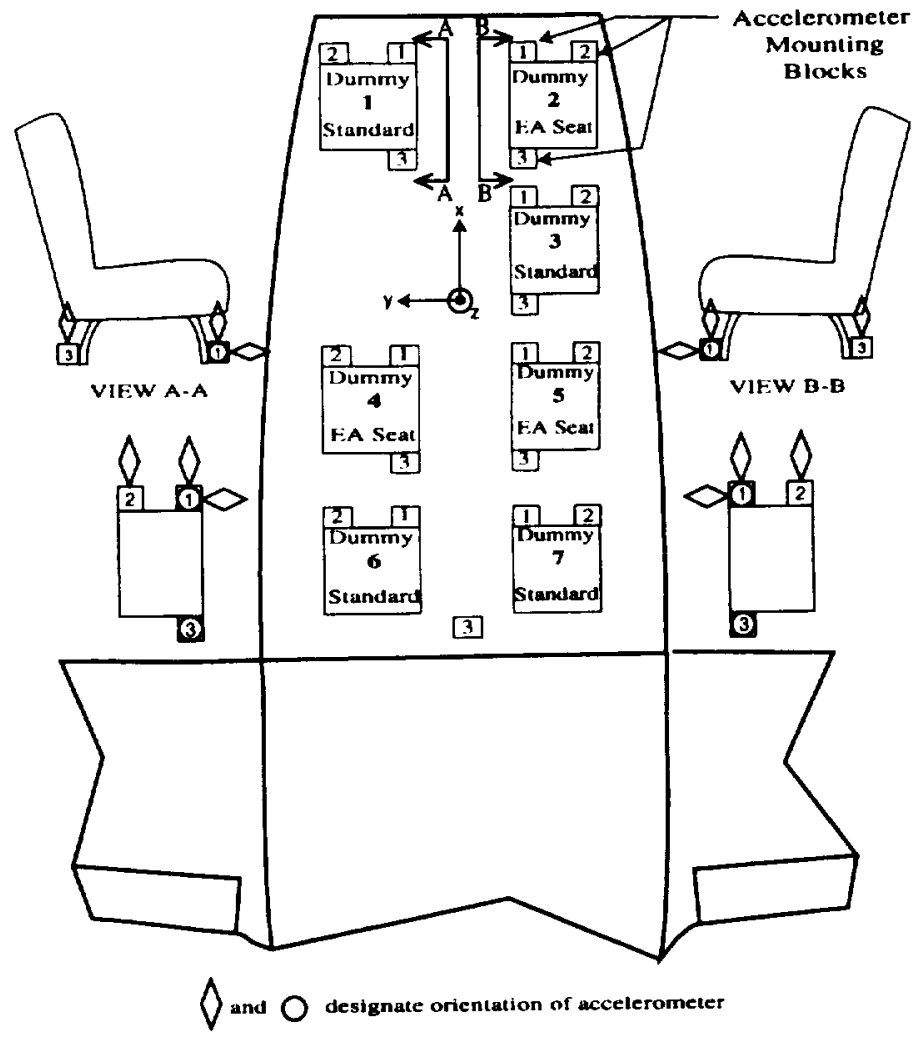

(a) Schematic of seat locations and onboard accelerometer locations and orientations.

Figure 4. Seating and instrumentation.
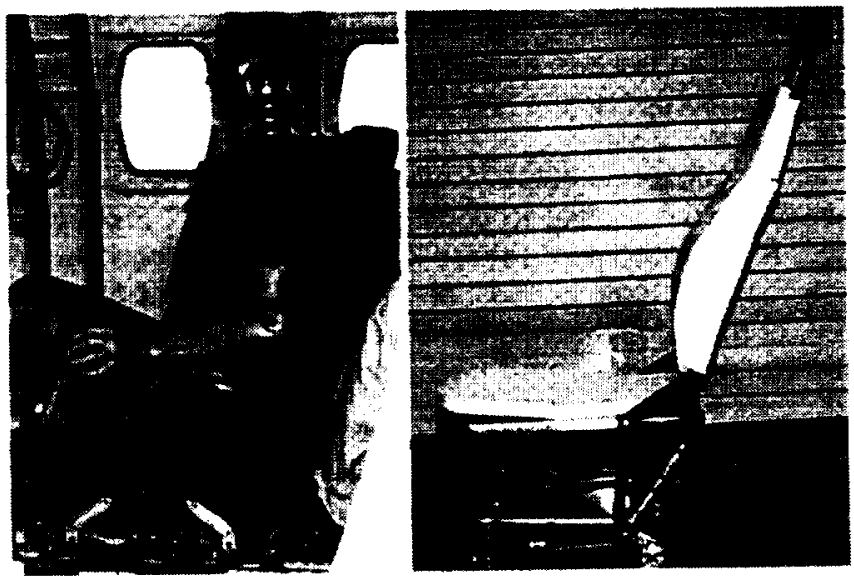

(b) Standard aircraft seat (left) and certified energy absorbing seat (right).

Figure 4. Concluded.

\section{INSTRUMENTATION}

The reference orientation axes and aircraft seat-rail mounted accelerometer locations are shown in Figure $4 . X$ is defined as the longitudinal direction, $Y$ is the lateral direction, and $Z$ is the vertical axis. In addition to the accelerometers mounted on the aircraft, occupants $1,2,4,5,6$ and 7 (50 percentile Hybrid 11 anthropomorphic dummies) were equipped with a lumbar load cell and accelerometers in the head, chest, and pelvis. The orientations of the instrumentation are given in the dummy's body-axis system 
where $x$ is longitudinal, $y$ is lateral, and $z$ is vertical. Due to limits on the number of data acquisition channels, the dummies were not identically instrumented. The accelerometer quantities and their orientations for all occupants except occupant number 3 are given in Table $I$ in the Appendix. The number 3 occupant was a "stand alone" 50 percentile Hybrid III anthropomorphic dummy provided by a private company. Twenty-six channels of data acquired for the number 3 occupant were stored in a transient data recorder onboard the airplane. Data for all three orientations were collected from the head, chest, and pelvis. Data for all three load directions and six moments were collected from the neck and lumbar load cells. Two channels of data were acquired from uniaxial femur load cells.

Data from three strain gages mounted on the metal subfloor structure were acquired. The purpose of the strain gages was to obtain an impact reference time for the other onboard instrumentation. Time zero for the other onboard instrumentation is taken to be the time at which the first measurable strain was recorded. A total of 104 channels of data were recorded including radar data.

\section{PHOTOGRAPHIC COVERAGE}

Photographic coverage for the test was provided by 400 pictures per second (PPS) cameras, 20 PPS motion picture cameras, standard video, and $35 \mathrm{~mm}$ still cameras. Five onboard 400 PPS cameras were focused on specific areas of interest. One camera with a fisheye wide angle lens was mounted on the dash board of the airplane and photographed an overall view of the airplane interior. A second camera was mounted between occupants 1 and 2 and was focused on occupants 4 and 5 . A third camera was mounted on the floor behind occupant 1 and was focused on the lower half of seats 4 and 5 . The last two onboard cameras were mounted on the wing box behind seat 6 and were intended to photograph the airbag deployment.

Additional 400 PPS cameras and video cameras were located on the ground to photograph the overall crash event (i.e., front, rear, port side). The 20 PPS (70 $\mathrm{mm}$ format) cameras were used to make photographic prints of the event. The $35 \mathrm{~mm}$ still cameras were used to record pre-test work, post-test results, and some photographs during the test.

\section{RESULTS AND DISCUSSION}

TEST IMPACT CONDITIONS - The planned test conditions were to impact the aircraft with landing gear retracted onto a concrete surface at $88 \mathrm{ft} . / \mathrm{sec}$. along a $-20.6^{\circ}$ flight path with a $+20.6^{\circ}$ pitch angle relative to the flight path, zero degrees of roll and zero degrees of yaw. These conditions result in a vertical velocity of $31 \mathrm{ft} / \mathrm{sec}$. and a longitudinal velocity of $81 \mathrm{ft} . / \mathrm{sec}$. The $31 \mathrm{ft} . / \mathrm{sec}$. vertical velocity condition is the velocity change specified as part of the dynamic test requirements for general aviation seats.

The actual longitudinal velocity at impact was measured to be $80 \mathrm{ft} . / \mathrm{sec}$. from the radar instrument. The vertical velocity was determined to be approximately 30 $\mathrm{ft} / \mathrm{sec}$. from film analysis and accelerometer data integration. The impact attitude was zero degrees of pitch, zero degrees of roll, and yaw was less than 0.5 degree.

A series of photographs illustrating the crash sequence is shown in Figure 5. The photographs show the motion from the pull-back position through the slide-out after impact. In the last two photographs, a crack is visible running
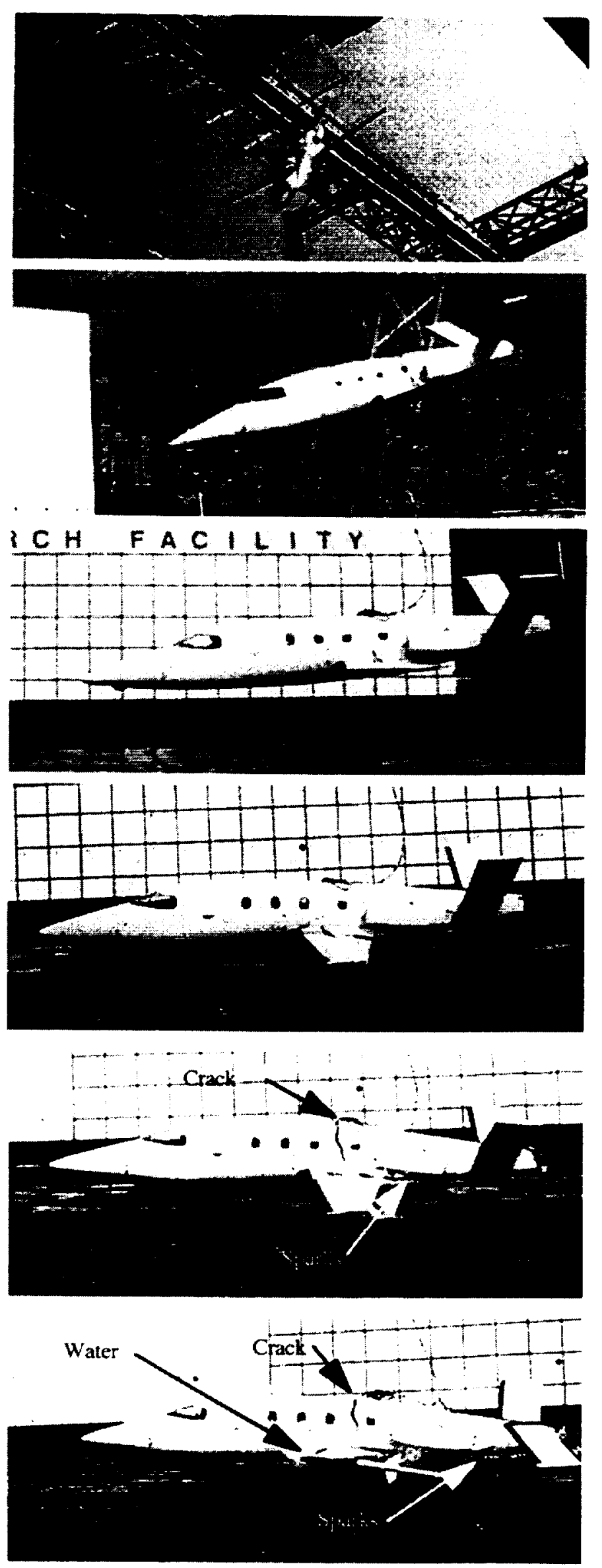

Figure 5. Crash sequence photographs. 
from the crown of the fuselage down to the wing. Sparks created by metal bolts contacting the concrete impact surface are noticeable just rearward of the wing. The bolts were used to secure a panel and were not added by NASA. Watersimulating fuel leaked from the wing after impact.

VISUAL ASSESSMENT OF STRUCTURAL DAMAGE - Post-test detail photographs of the exterior and interior damage are shown in Figures 6 and 7 . The circumferential crack running from the crown of the fuselage to the wing is shown in Figure 6(a). Examination of the high speed film confirms that the crack initiated at the umbilical access hole that was cut in the crown of the fuselage. A photograph of cracks around a window is shown in Figure 6(b). Note that three of the cracks originated at the corners of the window perhaps due to the stress concentrations at these locations. Similarly, cracks originating at the corners of the door opening were found. A photograph of the damage that occurred on the underside of the wing is shown in Figure 6(c). The water leakage that was shown in the crash sequence photographs was due to this damage.

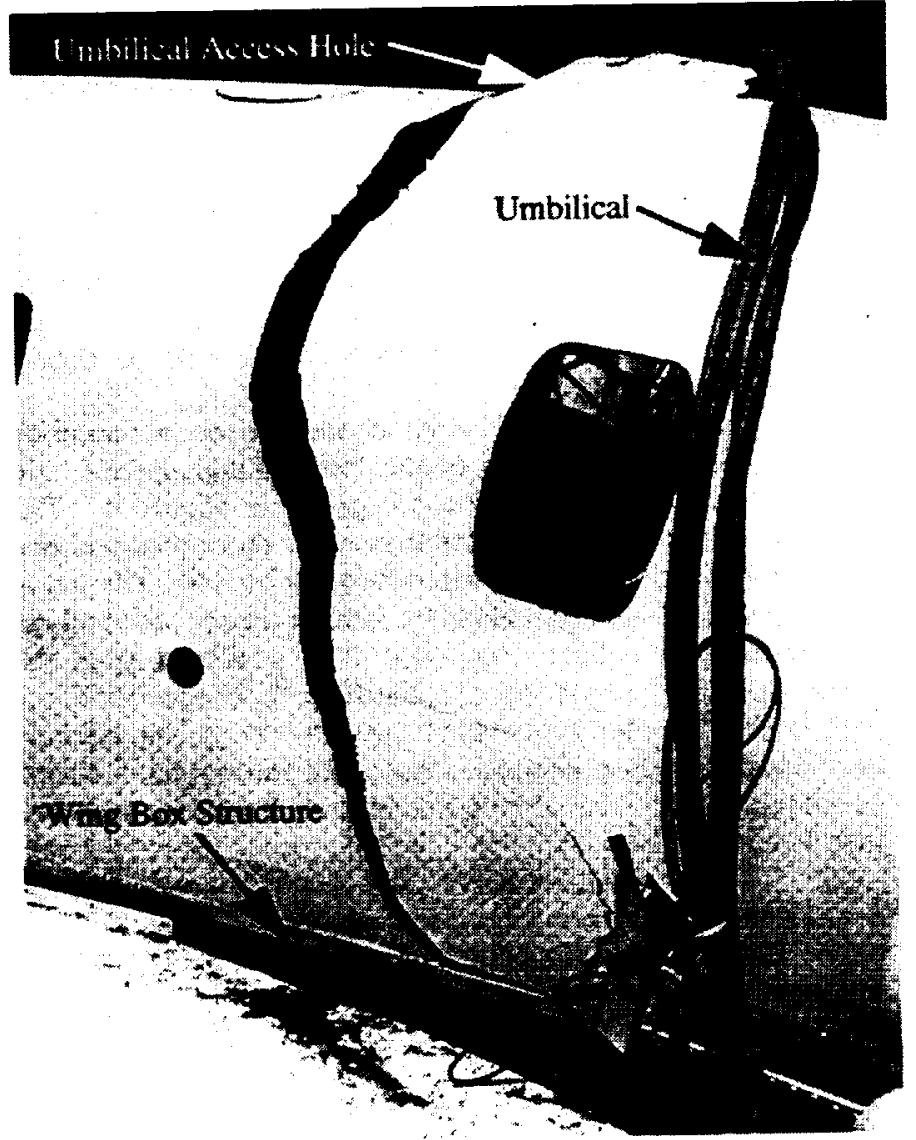

(a) Crack that initiated at the umbilical access hole.

Figure 6. Photographs of exterior damage.
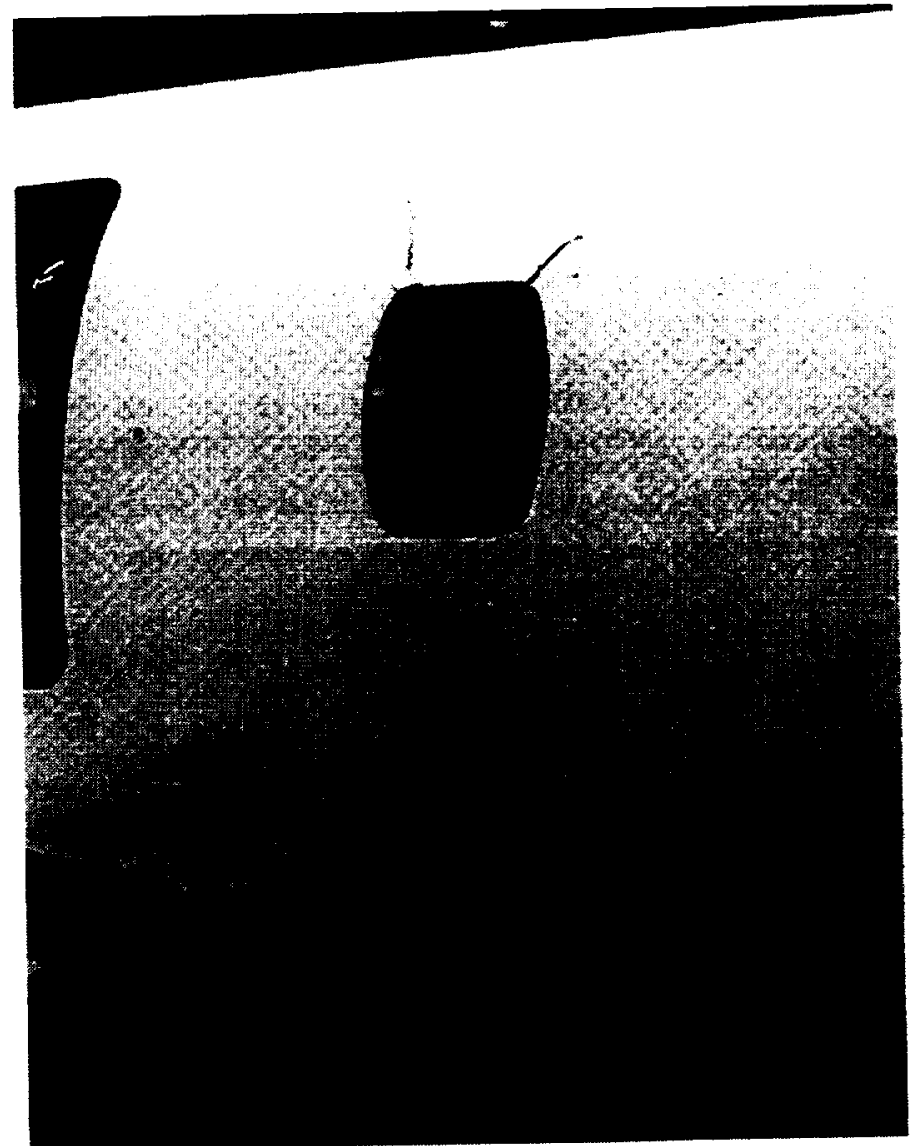

(b) Cracks around window.

Figure 6. Continued.

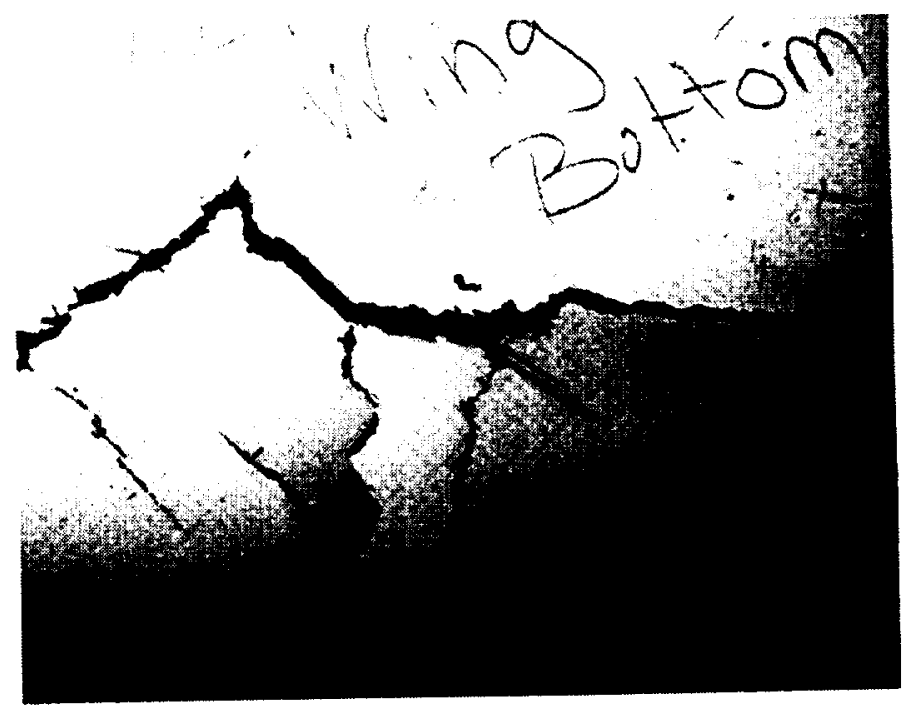

(c) Damage to bottom of left wing.

Figure 6. Concluded. 
A post-test photograph of the interior of the aircraft with the seats removed is shown in Figure 7(a). Very little damage to the metal floor, seat rail track, or aisle floor covering is noticeable and the cabin volume was maintained. A photograph of the interior after all of the floor material was removed is shown in Figure $7(\mathrm{~b})$. The frames failed along the center line of the aircraft and the same type of frame damage was found along the length of the aircraft. Details of this damage are shown in Figure 7(c). The frames appear to have failed in a brittle manner with little or no crushing or energy absorption. This failure is typical of the carbon fibre reinforced skin frame construction (Reference 5) used for the test vehicle.

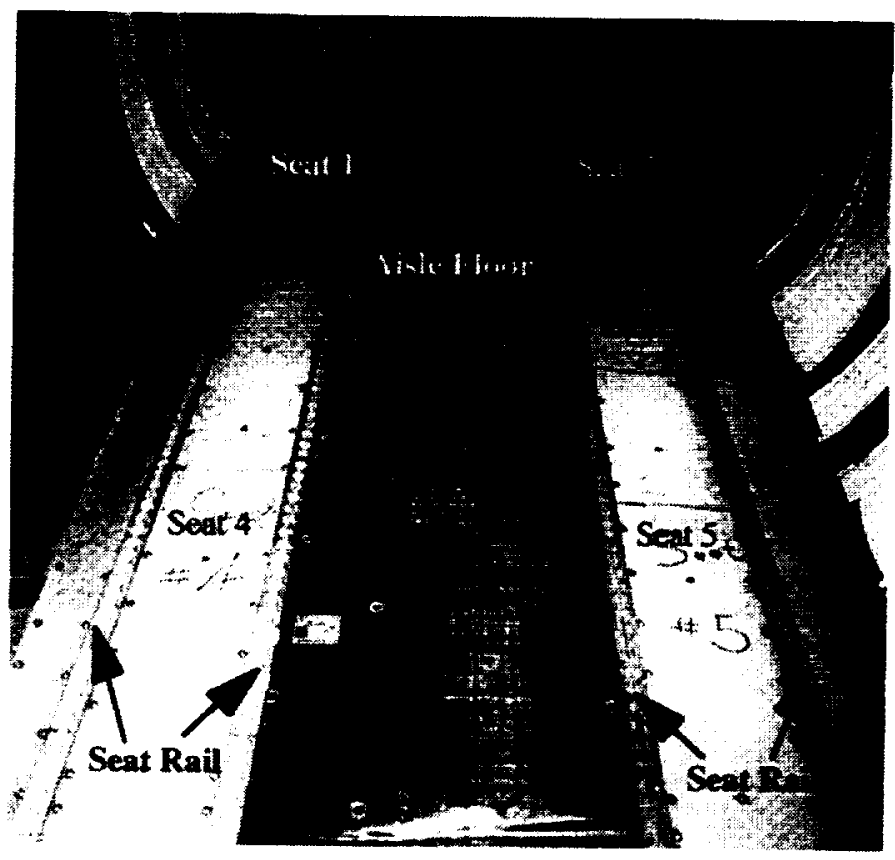

(a) Interior with seats removed.

Figure 7. Post-test interior photographs.

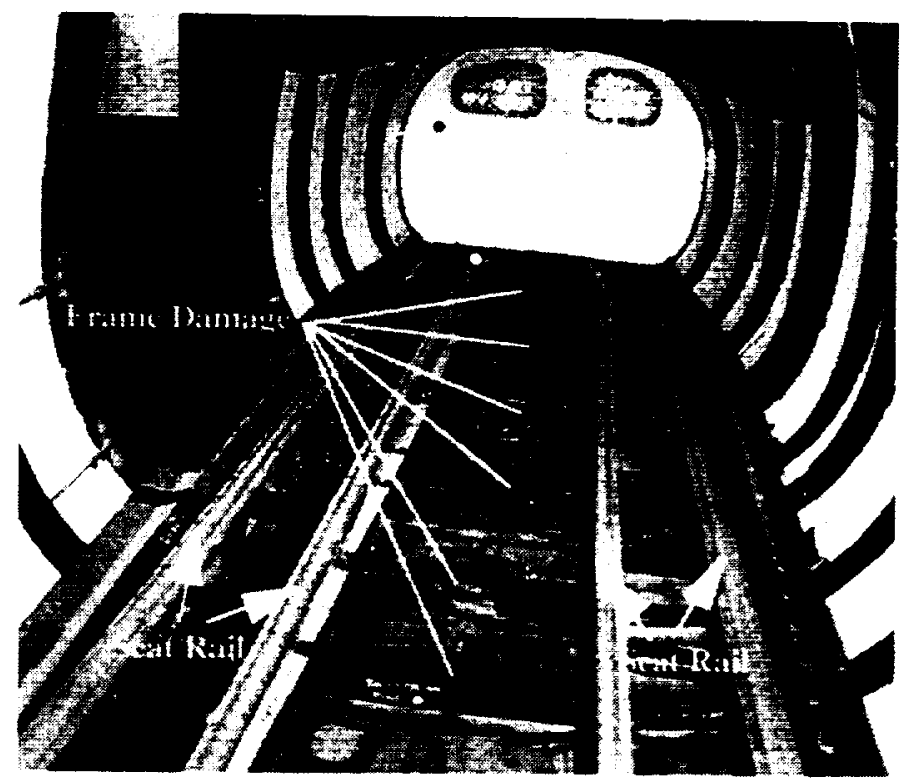

(b) Interior with floor removed.

Figure 7. Continued.

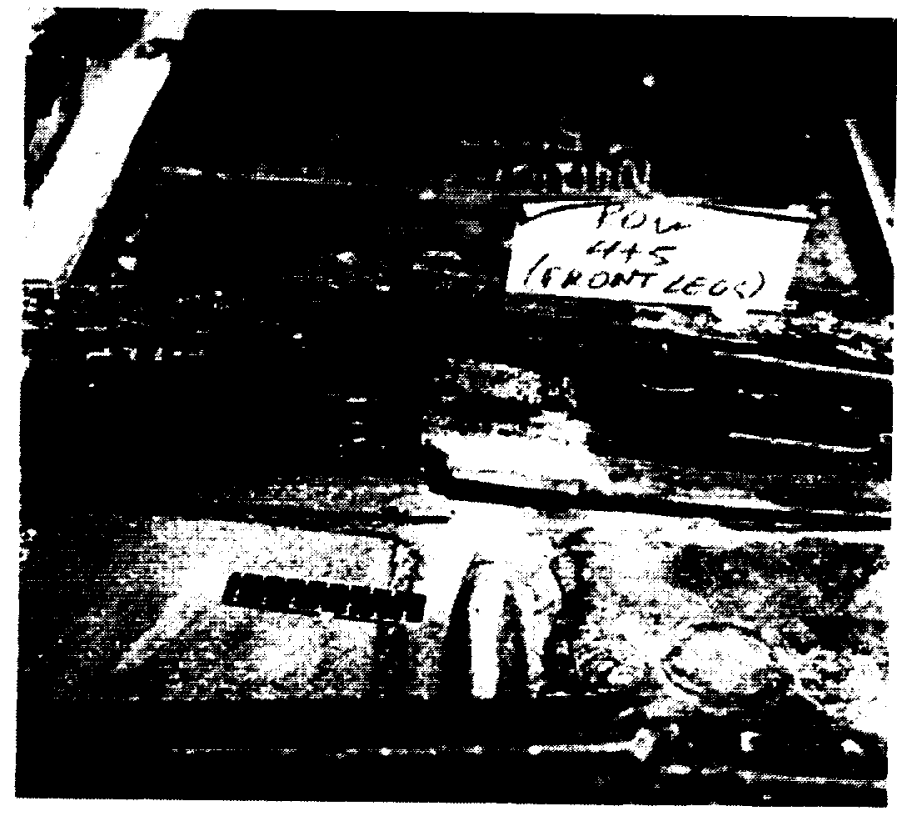

(c) Details of frame damage.

Figure 7. Concluded.

CRASH PULSES - The data presented in this section are typical of the data acquired throughout the aircraft. The high $\mathrm{g}$, high frequency data spikes associated with local structural responses are low energy and considered insignificant when compared with the overall response. Examples of these high frequency signals are noted in Figure 8.

Data were recorded from accelerometers mounted on the seat rail. Typical plots of the longitudinal, lateral, and vertical seat rail accelerations are given in Figure 8 . The vertical accelerations were more than twice those recorded in a similar test of an all-metallic aircraft (Reference 6). The initial vertical pulse lasted approximately seven milliseconds and the maximum acceleration exceeded $200 \mathrm{~g}$ where $\mathrm{g}$ is the acceleration due to gravity $\left(32.2 \mathrm{ft} / \mathrm{sec}^{2}\right)$. The longitudinal and lateral accelerations were not as severe as vertical accelerations. For example, the longitudinal and lateral accelerations did exceed $-50 \mathrm{~g}$ but the time durations were less than 3 milliseconds.

Typical accelerations and lumbar loads for the occupants are shown in Figures 9, 10, and 11. The vertical pelvis accelerations for occupants 1,2 , and 5 are given in Figure 9(a), 9(b) and 9(c) respectively. Occupant 1 was seated in a standard aircraft seat and occupants 2 and 5 were seated in energy absorbing (EA) seats. The maximum vertical accelerations for the energy absorbing seats are less than half that of the standard seat. The maximum acceleration for the standard seat occupant was $90 \mathrm{~g}$. Occupants 2 and 5 each had a maximum acceleration of $40 \mathrm{~g}$. The acceleration data from the developmental seat were disrupted by an intermittent noise signal, but the data trace characteristics are clear.

The longitudinal pelvis accelerations for the same three occupants are given in Figure 10. The maximum longitudinal accelerations for occupants 1,2 , and 5 are $35 \mathrm{~g}$, $15 \mathrm{~g}$, and $33 \mathrm{~g}$ respectively. Again, the high frequency, low energy data are considered insignificant when compared with the overall response. 
The trends in the pelvis vertical and longitudinal acceleration data are representative of the chest and head acceleration data. In general, the occupants in the EA seats had lower maximum accelerations. Only two channels of occupant lateral accelerations were recorded (See Table I). Because of the no-roll, no-yaw conditions of the test and limits on the number of channels available, the lateral accelerations were not recorded and will not be discussed.

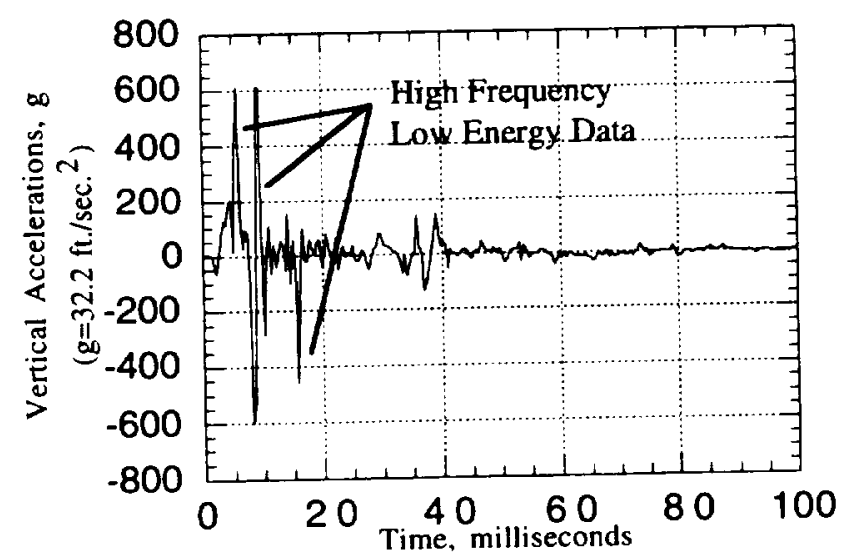

(a) Vertical seat rail acceleration.

Figure 8. Typical seat rail accelerations.

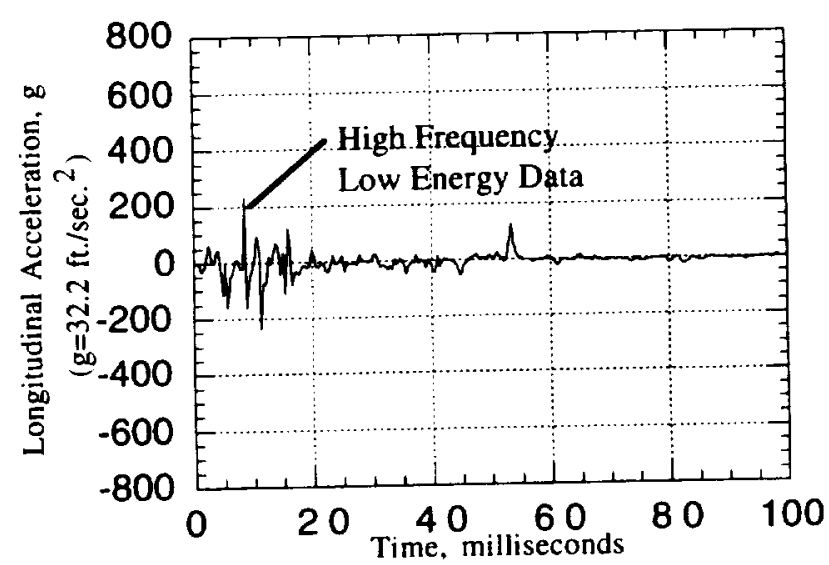

(b) Longitudinal seat rail acceleration.

Figure 8. Continued.

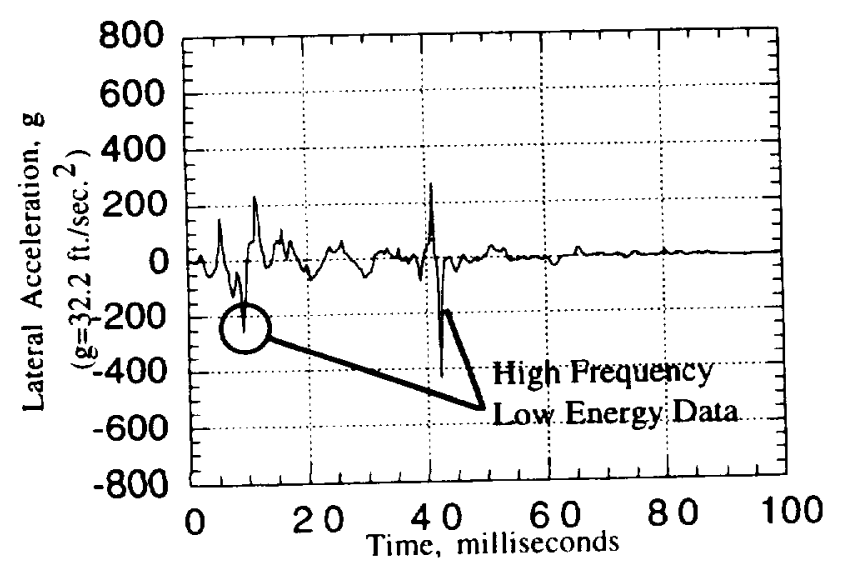

(c) Lateral seat rail acceleration.

Figure 8. Concluded.

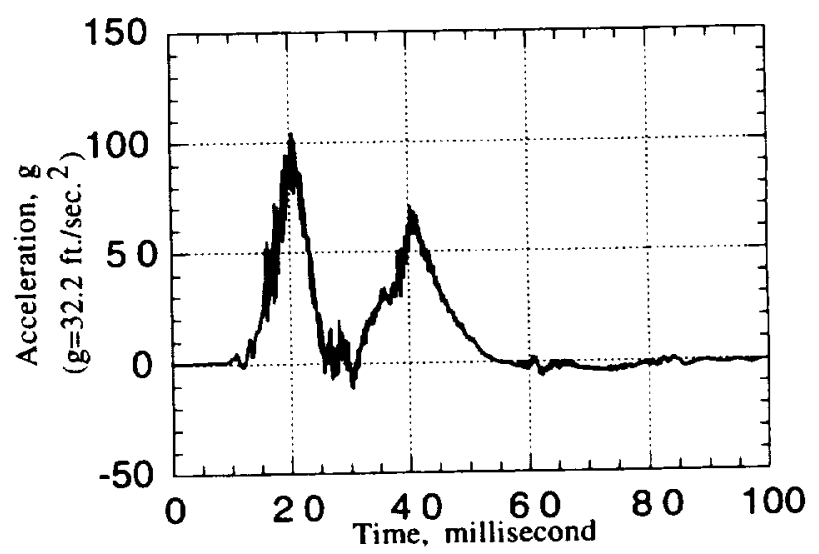

(a) Vertical pelvis acceleration for No. 1 occupant in standard seat.

Figure 9. Typical vertical pelvis accelerations.

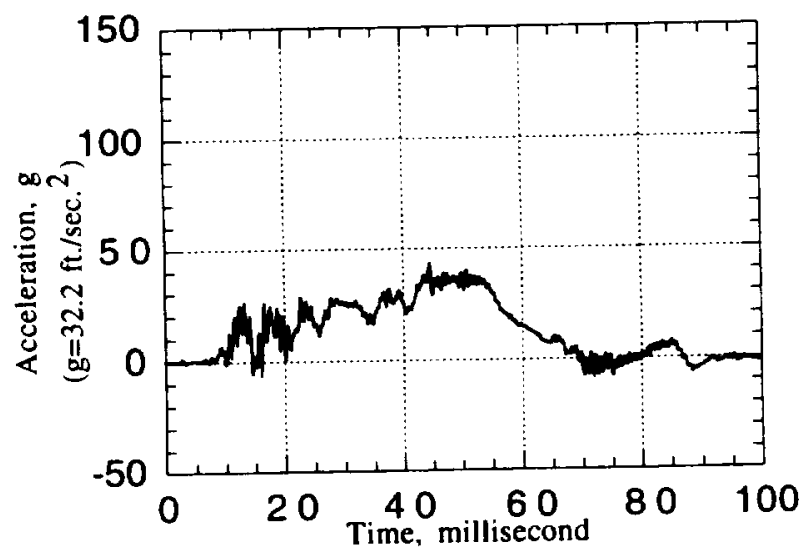

(b) Vertical pelvis acceleration for No. 2 occupant in energy absorbing seat.

Figure 9. Continued.

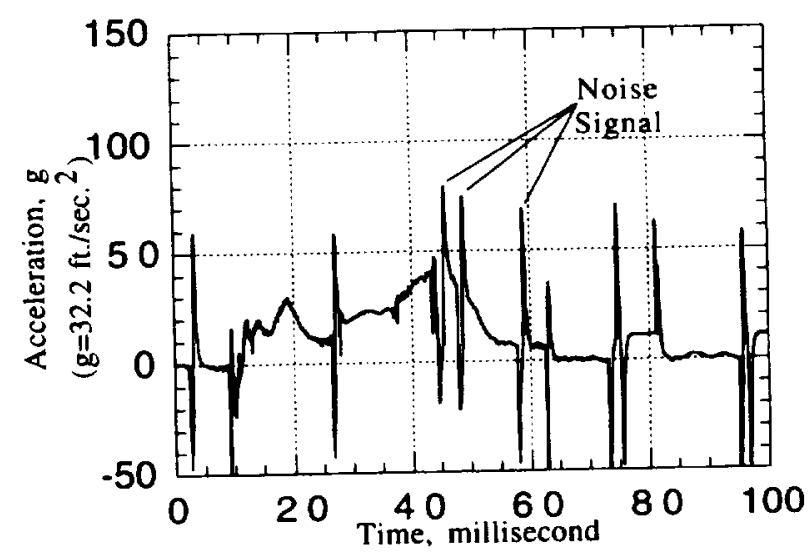

(c) Vertical pelvis acceleration for No. 5 occupant in a developmental energy absorbing seat.

Figure 9. Concluded. 


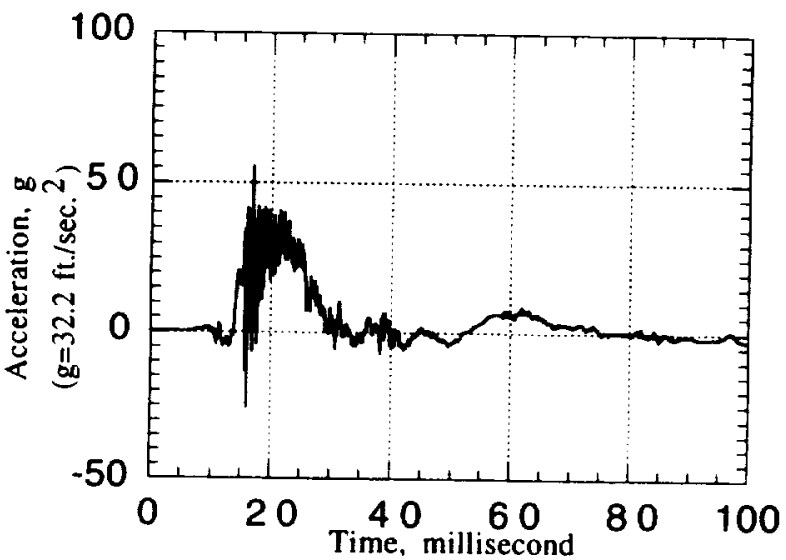

(a) Longitudinal pelvis acceleration for No. 1 occupant in standard seat.

Figure 10. Typical longitudinal pelvis accelerations.

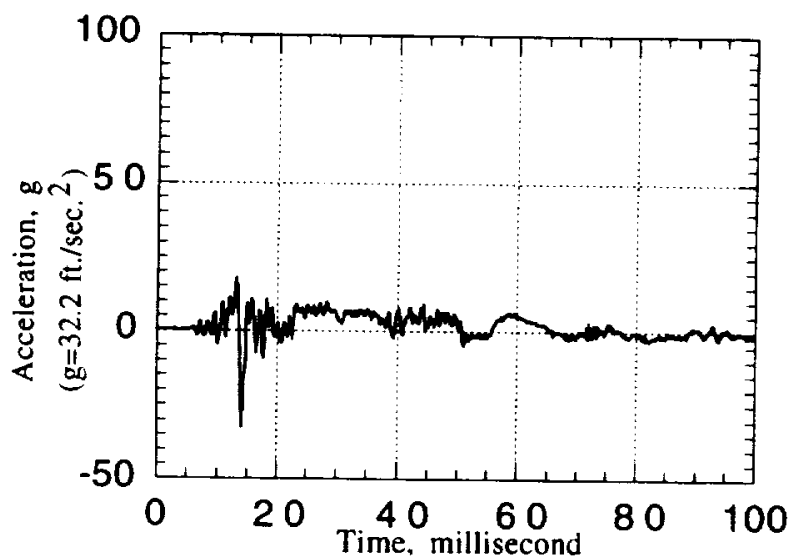

(b) Longitudinal pelvis acceleration for No. 2 occupant in an energy absorbing seat.

Figure 10. Continued.

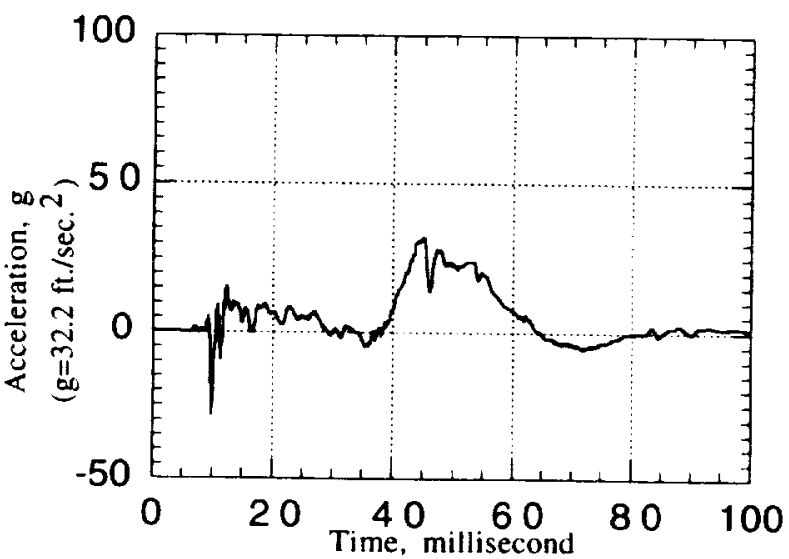

(c) Longitudinal pelvis acceleration for No. 5 occupant in developmental energy absorbing seat.

Figure 10. Concluded.

A comparison of the vertical lumbar loads for occupants 1,2 and 5 is shown in Figure 11. These results indicate that an EA seat can significantly reduce the lumbar loads. However, all seven occupants exceeded the $-1500 \mathrm{lb}$. spinal limit generally accepted as the on-set for injury to the spine and specified as the fail/pass limit for seat testing (Part
23 regulations). Occupant 1 had a maximum load of over $-3000 \mathrm{lb}$., and for 10 milliseconds the load exceeded $-2000 \mathrm{lb}$. Occupant 2 had a maximum load of approximately $-1600 \mathrm{lb}$., and sustained $-1600 \mathrm{lb}$. for approximately 12.5 milliseconds. Occupant 5 had a maximum load of approximately $-2100 \mathrm{lb}$., and the load exceeded $-1500 \mathrm{lb}$. for 15 milliseconds.

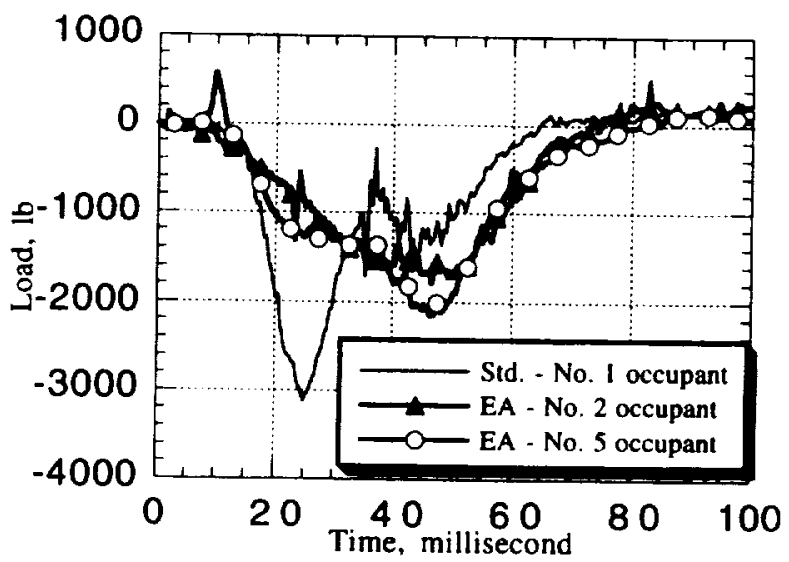

Figure 11. Typical vertical lumbar loads for standard seats and energy absorbing (EA) seats.

\section{SUMMARY AND CONCLUSIONS}

A general aviation airplane with a composite wing, fuselage and empennage but with metal floor beams was crash tested at the NASA Langley Research Center Impact Dynamics Research Facility. It was found that the accelerations on the floor of this composite aircraft were much higher than those for comparable all-metallic aircraft. The subfloor structure did not crush but failed in a brittle manner, and very little energy was absorbed. Therefore, this type of composite aircraft structural design is not considered the optimum composite design for crashworthiness. However, post-crash integrity and cabin volume were maintained.

The occupant response data indicate that the occupants seated in energy absorbing seats had considerably lower maximum accelerations and lumbar loads than those seated in a standard aircraft seat. However, lumbar loads for all occupants exceeded the $-1500 \mathrm{lb}$. spinal limit. If the subfloor had been an energy absorbing design, it would be expected that the occupants would have been exposed to lower accelerations and loads.

\section{REFERENCES}

1. Vaughan, Victor L., and Alfaro-Bou, Emilio, "Impact Dynamics Research Facility for Full-Scale Aircraft Crash Testing," NASA TN D-8179, April 1976.

2. Jones, Lisa E., and Fasanella, Edwin L., "Instrumentation and Data Acquisition for Full-Scale Aircraft Crash Testing," 39th International Instrumentation Symposium, Albuquerque, New Mexico, Paper No. 93-133, May 1993.

3. Hart-Smith, L. J., "Design and Development of the First Lear Fan All-Composite Aircraft," Presented to the Institution of Mechanical Engineers Conference on Design in Composite Materials, London, England, March 7-8, 1989. Douglas Paper No. 8184. 
4. Hooper, Steve, Holmes, Michael, Margaritti, Anastasia, and Nicholson, Mark, "The Design and Development of an Energy Absorbing Commuter Seat. Impact Dynamics," To be presented at the 1995 SAE General, Corporate and Regional Aviation Meeting and Exposition, Wichita, Kansas, May 3-5, 1995.

5. Boitnott, Richard L., and Fasanella, Edwin L., "Impact Evaluation of Composite Floor Sections," SAE Transactions Journal of Aerospace, Vol. 98, 1989, Pages 7184.

6. Vaughan, Victor L., and Alfaro-Bou, Emilio, "Light Airplane Crash Tests at Three Pitch Angles," NASA Technical Paper 1481, November 1979. 


\section{APPENDIX}

Table I

\begin{tabular}{|c|c|c|c|}
\hline $\begin{array}{c}\text { Dummy } \\
\text { Location }\end{array}$ & $\begin{array}{c}\text { Total Number and } \\
\text { Orientation of } \\
\text { Accelerometers in } \\
\text { Head }\end{array}$ & $\begin{array}{c}\text { Total Number and } \\
\text { Orientation of } \\
\text { Accelerometers in } \\
\text { Chest }\end{array}$ & $\begin{array}{c}\text { Total Number and } \\
\text { Orientation of } \\
\text { Accelerometers in } \\
\text { Pelvis }\end{array}$ \\
\hline 1 & $3-x, y, z$ & $2-x, z$ & $2-x, z$ \\
\hline 2 & $3-x, y, z$ & $2-x, z$ & $2-x, z$ \\
\hline 4 & $2-x, z$ & $2-x, z$ & $2-x, z$ \\
\hline 5 & $2-x, z$ & $2-x, z$ & $2-x, z$ \\
\hline 6 & $2-x, z$ & $2-x, z$ & - \\
\hline 7 & $2-x, z$ & $2-x, z$ & - \\
\hline
\end{tabular}




\title{
Overview of Structural Behavior and Occupant Responses from a Crash Test of a Composite Airplane
}

\author{
Lisa E. Jones and Huey D. Carden \\ NASA Langley Research Center
}

\section{ABSTRACT}

As part of NASA's composite structures crash dynamics research, a general aviation aircraft with composite wing, fuselage and empennage (but with metal subfloor structure) was crash tested at the NASA Langley Research Center Impact Dynamics Research Facility. The test was conducted to determine composite aircraft structural behavior for crash loading conditions and to provide a baseline for a similar aircraft test with a modified subfloor. Structural integrity and cabin volume were maintained. Lumbar loads for dummy occupants in energy absorbing seats were substantially lower than those in standard aircraft seats; however, loads in the standard seats were much higher than those recorded under similar conditions for an all-metallic aircraft.

\section{INTRODUCTION}

In cooperation with U.S. industry and the FAA, NASA is developing advanced structures technology for future general aviation aircraft that will be used for business and personal transportation. NASA is developing this technology to help the general aviation industry develop and apply newly emerging technologies to improve the affordability, safety, utility and environmental acceptability of U.S. produced general aviation aircraft. To support the safety related issues, tests of composite structures are being conducted at NASA Langley Research Center to provide a database on the behavior of composite structures which have not necessarily been designed for energy absorption. These data would guide the development of concepts that improve vehicle crash response and behavior and improve energy absorption management during crash conditions.

NASA Langley Research Center recently acquired two full-scale composite test airplane structures for crash test evaluation. One airplane was tested in essentially an "as is" condition to provide a baseline for an additional test with a modified subfloor structure that improves energy absorption. Through this process the potential improvements in reducing crash loads to occupants for a crash condition will be demonstrated. Such results will form the basis for new design concepts for aircraft that include energy absorbing structural concepts. The concepts will be included at the outset of the design process rather than in a retrofit design.
The present paper describes the structural test and several other safety related technologies included in the test. There were three different energy absorbing seats onboard the airplane as well as a bulkhead airbag experiment. Two of the seats and the bulkhead airbag are developmental designs, while the other energy absorbing seat is certified under Part 23 of the Federal Air Regulation. The data presented in this paper represent typical structural and occupant accelerations, and occupant lumbar loads from the test.

\section{TEST FACILITY}

The NASA Langley Research Center Impact Dynamics Research Facility (IDRF) was used to test the airplane studied in this investigation and is shown in Figure 1. The facility is 240 feet high, 400 feet long, and 265 feet wide at the base. An 8-inch-thick reinforced concrete impact surface is centered under the facility gantry and is approximately 396 feet long and 29 feet wide. The movable backboard is used for photographic clarity and camera referencing.

For a test at the IDRF, the test vehicle is suspended from two swing cables, pulled back, and released to allow the test vehicle to swing into the impact surface (Figure 2). Free flight conditions are established when the swing cables are pyrotechnically separated from the vehicle just prior to the impact. Knowing the attitude, cable forces, and flight path velocity desired for the test, calculations are made to determine the necessary swing and pull-back cable size and lengths, and the release height of the test vehicle. Details of these calculations are available in Reference 1.

Onboard transducers are wired to an onboard junction box for data acquisition. An umbilical cable connects the onboard junction box to a junction box in the superstructure of the gantry (Figure 2) which is connected to a junction box in the control room. Through the umbilical, an external power supply is used to power voltage regulator cards that provide precision excitation for the onboard instrumentation. The output signals from the onboard instruments are transmitted through the umbilical back to the control room where the signals are recorded by a digital data acquisition system. Up to 96 channels of data can be collected at a typical rate of 4000 samples per second (References 1 and 2 ). 


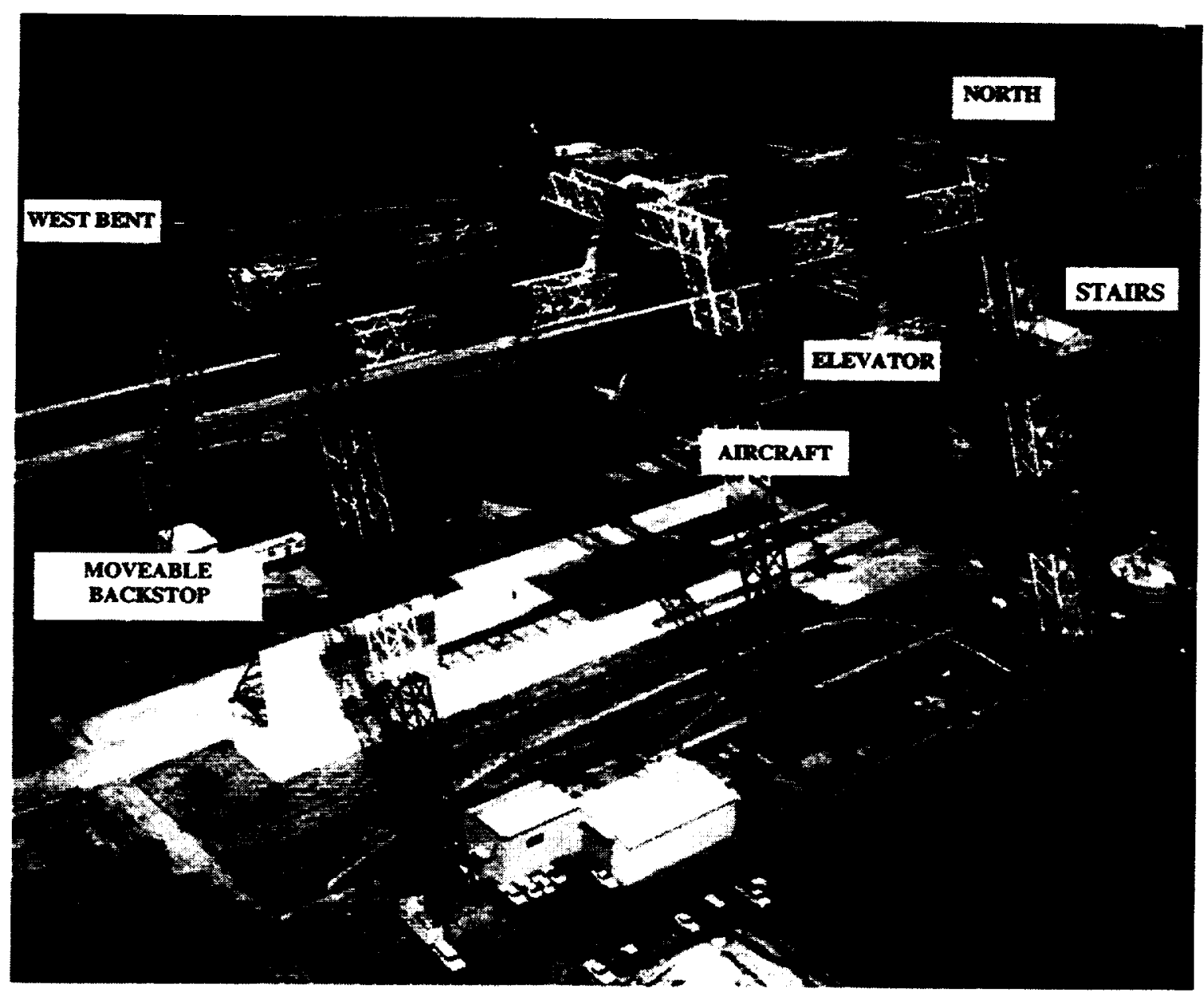

Figure 1. NASA Langley Research Center Impact Dynamics Research Facility.

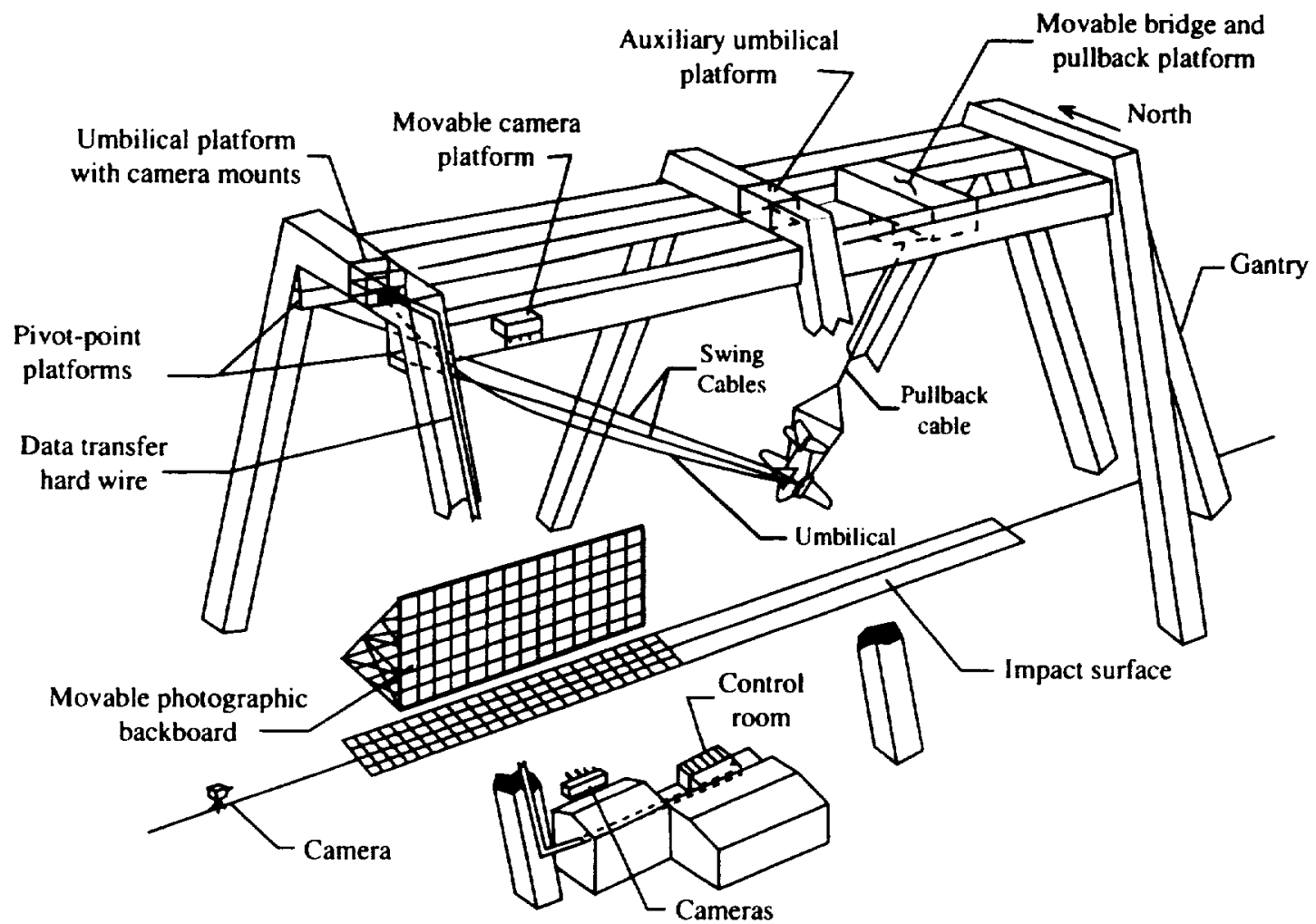

Figure 2. Diagram of Impact Dynamics Research Facility. 